\title{
The impact of the duration of the palliative care period on cancer patients with regard to the use of hospital services and the place of death: a retrospective cohort study
}

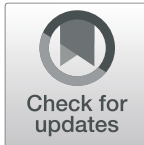

Outi M. Hirvonen ${ }^{1 *}$, Riikka-Leena Leskelä ${ }^{2}$, Lotta Grönholm³ ${ }^{3}$ Olli Haltia ${ }^{4}$, Samuli Voltti ${ }^{2}$, Kristiina Tyynelä-Korhonen ${ }^{5}$, Eeva K. Rahko ${ }^{6}$, Juho T. Lehto ${ }^{7}$ and Tiina Saarto ${ }^{3}$

\begin{abstract}
Background: In order to avoid unnecessary use of hospital services at the end-of-life, palliative care should be initiated early enough in order to have sufficient time to initiate and carry out good quality advance care planning (ACP). This single center study assesses the impact of the PC decision and its timing on the use of hospital services at $E O L$ and the place of death.

Methods: A randomly chosen cohort of 992 cancer patients treated in a tertiary hospital between Jan 2013 -Dec 2014, who were deceased by the end of 2014, were selected from the total number of 2737 identified from the hospital database. The PC decision (the decision to terminate life-prolonging anticancer treatments and focus on symptom centered palliative care) and use of PC unit services were studied in relation to emergency department (ED) visits, hospital inpatient days and place of death.

Results: A PC decision was defined for $82 \%$ of the patients and 37\% visited a PC unit. The earlier the PC decision was made, the more often patients had an appointment at the PC unit (> 180 days prior to death $72 \%$ and $<14$ days $10 \%$ ). The number of ED visits and inpatient days were highest for patients with no PC decision and lowest for patients with both a PC decision and an PC unit appointment (60 days before death ED visits 1.3 vs 0.8 and inpatient days 9.9 vs 2.9 respectively, $p<0.01$ ). Patients with no PC decision died more often in secondary/tertiary hospitals (28\% vs. $19 \%$ with a PC decision, and $6 \%$ with a decision and an appointment to a PC unit).
\end{abstract}

Conclusions: The PC decision to initiate a palliative goal for the treatment had a distinct impact on the use of hospital services at the EOL. Contact with a PC unit further increased the likelihood of EOL care at primary care.

Keywords: Palliative care, Cancer, End-of-life care, Hospitalization, Emergency department, Place of death, Advance care planning, Finland

\footnotetext{
* Correspondence: outi.hirvonen@tyks.fi

${ }^{1}$ Department of Oncology and Radiotherapy, Turku University Hospital and Department of Clinical Oncology, University of Turku, PO Box 52, Fl-20521 Turku, Finland

Full list of author information is available at the end of the article
}

(c) The Author(s). 2020 Open Access This article is licensed under a Creative Commons Attribution 4.0 International License, which permits use, sharing, adaptation, distribution and reproduction in any medium or format, as long as you give appropriate credit to the original author(s) and the source, provide a link to the Creative Commons licence, and indicate if changes were made. The images or other third party material in this article are included in the article's Creative Commons licence, unless indicated otherwise in a credit line to the material. If material is not included in the article's Creative Commons licence and your intended use is not permitted by statutory regulation or exceeds the permitted use, you will need to obtain permission directly from the copyright holder. To view a copy of this licence, visit http://creativecommons.org/licenses/by/4.0/. The Creative Commons Public Domain Dedication waiver (http://creativecommons.org/publicdomain/zero/1.0/) applies to the data made available in this article, unless otherwise stated in a credit line to the data. 


\section{Background}

Cancer patients are often admitted to hospital care during the last months of their life [1]. In some cases, this is unavoidable, but an increased number of emergency department (ED) visits, inpatient hospital admissions, or dying in an acute-care setting is also a characteristic of insufficient palliative care (PC) for patients with advanced cancer approaching their end-of-life (EOL) [2, 3]. In contrast, patients receiving in-home PC are less likely to visit the ED or to be admitted to a hospital than those receiving standard care $[4,5]$. Furthermore, communitybased palliative home-care services are not only associated with reduced ED visits, but also with fewer and shorter hospitalizations, lower risk of intensive care unit (ICU) admission, as well as an increased likelihood of a home death [6-9].

It has been demonstrated that early integrated PC leads to less aggressive EOL care, including reduced chemotherapy and longer hospice care [10]. The longer the hospice care period the better the quality of life [11]. Early integrated palliative care also reduces the rates of hospitalization and ED visits $[10,12]$. Thus, palliative decision making is preponed.

Internationally, the terminology of the $\mathrm{PC}$ period and its timing and content is somewhat confusing. In the Lancet Oncology Commission paper [13] the terms are defined based on the treatment intention: curative, life prolonging, or palliative. However, $\mathrm{PC}$ can be integrated at any stage of the disease trajectory, irrespective of the primary intention of the treatment [13]. When the primary treatment goal is set to palliative, and the disease modifying treatments end, the period of PC begins. In our study this moment is called the PC decision.

An earlier transition into PC can be one way of reducing the use of hospital services at the EOL $[2,3]$. It gives more time to initiate and carry out advance care planning (ACP) including a connection to primary care or a hospice as well as organizing care in the home, if possible. ACP is important; although it can be conducted by general practitioners, $\mathrm{PC}$ specialists are highly skilled in this area. Thus, an appointment at a PC unit may offer one approach for improving the quality and completion of the ACP documentation [14]. Consequently, the service needs of the patients at the EOL should be addressed outside both the ED and the secondary or tertiary care hospital. The site of death may then indicate the quality of end-of-life care, as the majority of patients with the serious illness want to die at home rather than in an institutional setting [11].

Although there are studies showing that an earlier introduction (of one to more than three months prior to death) of PC is associated with improved EOL care, in terms of fewer hospitalizations and increased likelihood of dying at home or in a hospice [15-18], there is no data, to our knowledge, regarding the impact of the transition from life-prolonging anticancer treatments to PC and its timing on the hospitalizations and site of death in cancer patients.

In our earlier study [19], we reported that PC decisions done within the last month prior to death were associated with anti-cancer treatments continuing until close to death, and the access to a PC unit becoming more unlikely. Therefore, a well-timed decision to initiate a palliative period might also be related to more appropriate treatment and resource usage at the EOL.

The aim of this study was to evaluate whether the PC decision and a referral to a PC unit have an impact on the use of hospital services at the EOL and on the place of death.

\section{Methods}

\section{Cohort selection}

This cohort consists of a sample of patients with a cancer diagnosis (ICD-10 C00-C96) who had received treatment in the Department of Oncology at Helsinki University Central Hospital ( $\mathrm{HUCH}$ ) between January 1 -December 31, 2013 and were deceased by December 31, 2014. The total number of patients fulfilling the criteria was 2737 and of these, 992 were randomly selected for the study cohort from the hospital register. Randomization was done by sorting the patients in the order of their pseudonymized identifier, creating a random order. Finally 949 patients were included; 43 patients with non-malignant primary cause of death or pediatric patients were excluded. This retrospective study was done with the permission of the authorities of HUCH. According to Finnish legislation, no ethics committee approval was needed.

Finnish cancer patients are treated mainly at public university and central hospitals. $\mathrm{HUCH}$ is the largest university hospital in Finland being responsible for the cancer care of a population of approximately 1.6 million in Southern Finland. HUCH is governed by the representatives of all the municipalities in the region and $\mathrm{HUCH}$ provides all secondary and tertiary care for these municipalities. During the time of this study, the $\mathrm{HUCH}$ Department of Oncology provided radiation therapy treatments for all cancer patients and systemic cancer treatments for most cancer patients (not for pediatric (< 18 years), hematological, gynecological or lung cancer patients). There is a PC outpatient unit in the Department of Oncology, but municipalities, who in Finland organize primary care, are responsible for EOL care. However, early integrated PC was not systematically provided at $\mathrm{HUCH}$ at the time of the study.

\section{Data sources and collection}

The data and data sources used in the study are the same as in [19], but some new variables were considered 
in addition to those in [19]: do not resuscitate (DNR) decisions, visits to the ED in secondary/tertiary hospitals, inpatient episodes in secondary/tertiary hospitals, appointments to $\mathrm{PC}$ units, timing of the PC decision, and the date and place of death. Most data used in this study was available in a structured format and exported directly from the electronic medical records. Information on the PC decision, DNR decision and place of death were manually extracted by two of the authors ( $\mathrm{LH}$ and $\mathrm{OH})$. Due to the nature of the data, there were no missing values as it is mandatory to record all the parameters used. The only missing or imprecise information was in the death certificates concerning the place of death $(3 \%)$.

The cancer diagnoses were grouped in the same way as in [19] into 13 groups. When the patient had more than one malignancy, the cancer diagnosis was recorded to match the primary cause of death.

\section{Division of categories and service usage}

The service usage of all patients was studied 14, 30, and 60 days before the time of death. Service usage is enumerated by two measures, the number of visits to an emergency department ('ED visits') and the number of nights spent in the hospital ('inpatient days'). The places of death were categorized in five categories: home, primary care wards, secondary or tertiary care wards, hospices, and nursing homes. In the 24 municipalities of Southern Finland, at the time of the study, there was one hospice, one PC ward in primary care and seven home care teams specialized in PC.

The PC decision and the PC period are defined as in [19]. For the purposes of this study patients were divided into three separate categories: 'no PC decision', 'PC decision', and 'PC decision and appointment to a PC unit'. This definition is operated in a dynamic fashion in the analyses to ensure a correct chronology of events. For example, if patients have a $\mathrm{PC}$ decision made 40 days prior to death and have visited the PC unit 20 days before death, they will be categorized as 'PC decision' for the analysis of events 30 days prior to death, and as 'PC decision and appointment to a PC unit' for the analysis of events 14 days prior to death. However, when considering service usage 60 days prior to death, they will be categorized as 'no PC decision', as at that time neither the PC decision nor the appointment have taken place. Thus, in each analysis, the patients were categorized depending on the timing of the PC decision and PC unit appointment with respect to the time period studied.

\section{Statistical analysis}

Means, standard deviations, and distributions were used for patient characteristics. The frequency of DNR decisions and the distribution of the places of death were analyzed by cross-tabulation. Pairwise Pearson's chi squared tests were conducted to statistically test for the differences between the three categories with respect to DNR and place of death. The difference between the three categories with respect to ED and inpatient service usage was tested with pairwise t-tests (pooled standard deviation and p-values adjusted with the Holm method). The association of the PC decision and PC unit appointments with hospital service usage was also tested with linear regression models including control variables (age, time from diagnosis to death, and cancer diagnosis). Logarithmic transformations for the dependent and independent variables were conducted to normalize the residuals in the regression models. All analyses were performed using R-studio version 1.1.447 and its packages.

\section{Results}

Characteristics of the patients are presented in Table 1. For most patients $(82 \%)$ a PC decision was made, and $37 \%$ of the patients had an appointment at the PC unit. The frequency of DNR decisions in the 'No PC decision at all' category is statistically significantly smaller than in the 'PC decision at some point' category $(p<0.01)$, as is the frequency of DNR decisions in the 'PC decision and appointment to a PC unit at some point' category when compared to the 'PC decision at some point' category $(p<0.05)$. However, the differences in the frequency of DNR decisions is not statistically significant between the 'No PC decision at all' and the 'PC decision and appointment to a PC unit at some point' categories. The pairwise comparisons of the distributions of the places of death between the three patient categories are all statistically significant $(p<0.01)$.

\section{Place of death}

The association of the PC decision and the PC unit appointment with the place of death is also presented in Table 1 . The significant difference between the categories is that patients with no PC decision died more often in secondary/tertiary care wards ( $28 \%$ vs. $19 \%$ and $6 \%$, respectively) whereas patients with a PC decision or both a PC decision and a PC unit appointment were more likely to die in primary care wards $(46 \%$ vs. $56 \%$ and $59 \%$, respectively).

\section{Resource use}

Table 2 describes the timing of the PC decision with respect to the time of death, and the proportion of patients visiting the $\mathrm{PC}$ unit. The earlier the $\mathrm{PC}$ decision was made, the more often patients also visited the PC unit.

Figures 1 and 2 depict the average resource usage of the three categories of patients in the hospital ED and inpatient wards 14, 30 and 60 days prior to death. The average number of ED visits (Fig. 1) and the average number of inpatient days (Fig. 2) were highest for 
Table 1 Characteristics of the patients

\begin{tabular}{|c|c|c|c|c|}
\hline \multirow[b]{2}{*}{ Measure } & \multicolumn{3}{|l|}{ Category } & \multirow[b]{2}{*}{ Total } \\
\hline & No $P C$ decision at all & PC decision at some point & $\begin{array}{l}\text { PC decision and appointment } \\
\text { to a PC unit at some point }\end{array}$ & \\
\hline Number of patients, N (\%) & $176(19 \%)$ & $424(45 \%)$ & $349(37 \%)$ & $949(100 \%)$ \\
\hline \multicolumn{5}{|l|}{ Gender, N (\%) } \\
\hline Male & $86(49 \%)$ & $225(53 \%)$ & $188(54 \%)$ & $499(53 \%)$ \\
\hline Female & $90(51 \%)$ & $199(47 \%)$ & $161(46 \%)$ & $450(47 \%)$ \\
\hline Age (years) at death, mean (Stdev) & $64(11.9)$ & $67(11.8)$ & $68(12.5)$ & $67(12.1)$ \\
\hline \multicolumn{5}{|l|}{ Cancer diagnoses, N (\%) } \\
\hline Upper gastrointestinal & $29(16 \%)$ & $83(20 \%)$ & $106(30 \%)$ & $218(23 \%)$ \\
\hline Colorectal cancers & $17(10 \%)$ & $52(12 \%)$ & $54(15 \%)$ & $123(13 \%)$ \\
\hline Lung * & $27(15 \%)$ & $75(18 \%)$ & $16(5 \%)$ & $118(12 \%)$ \\
\hline Breast cancer & $24(14 \%)$ & $53(13 \%)$ & $29(8 \%)$ & $106(11 \%)$ \\
\hline Prostate cancers & $13(7 \%)$ & $19(4 \%)$ & $35(10 \%)$ & $67(7 \%)$ \\
\hline Cancers of urinary tract & $6(3 \%)$ & $29(7 \%)$ & $26(7 \%)$ & $61(6 \%)$ \\
\hline Primary CNS malignancies & $16(9 \%)$ & $30(7 \%)$ & $14(4 \%)$ & $60(6 \%)$ \\
\hline Lymphomas & $6(3 \%)$ & $20(5 \%)$ & $11(3 \%)$ & $37(4 \%)$ \\
\hline Invasive skin cancers & $6(3 \%)$ & $17(4 \%)$ & $9(3 \%)$ & $32(3 \%)$ \\
\hline Sarcomas & $5(3 \%)$ & $10(2 \%)$ & $15(4 \%)$ & $30(3 \%)$ \\
\hline Gynecological cancers * & $9(5 \%)$ & $8(2 \%)$ & $11(3 \%)$ & $28(3 \%)$ \\
\hline Head \& Neck (H\&N) & $8(5 \%)$ & $12(3 \%)$ & $8(2 \%)$ & $28(3 \%)$ \\
\hline Others & $10(6 \%)$ & $16(4 \%)$ & $15(4 \%)$ & $41(4 \%)$ \\
\hline Time (months) from diagnosis to death, mean (Stdev) & $33(44)$ & $37(43)$ & $41(46)$ & $37(44)$ \\
\hline DNR decision made, $\mathrm{N}$ (\% of category) & $77(44 \%)^{\mathrm{a}, \mathrm{c}}$ & $240(57 \%)^{a, b}$ & $171(49 \%)^{b, c}$ & $488(51 \%)$ \\
\hline \multicolumn{5}{|l|}{ Place of death, N (\%) } \\
\hline Home & $26(15 \%)$ & $37(9 \%)$ & $73(21 \%)$ & $136(14 \%)$ \\
\hline Hospice & $10(6 \%)$ & $53(13 \%)$ & $31(9 \%)$ & $94(10 \%)$ \\
\hline Nursing home & $3(2 \%)$ & $9(2 \%)$ & $7(2 \%)$ & $19(2 \%)$ \\
\hline Primary care ward & $81(46 \%)^{d}$ & $236(56 \%)^{d}$ & $205(59 \%)^{d}$ & $522(55 \%)$ \\
\hline Secondary / tertiary healthcare & $50(28 \%)^{d}$ & $80(19 \%)^{d}$ & $22(6 \%)^{d}$ & $152(16 \%)$ \\
\hline Unknown & $6(3 \%)$ & $9(2 \%)$ & $11(3 \%)$ & $26(3 \%)$ \\
\hline
\end{tabular}

* only patients receiving radiotherapy are included

a The difference between these groups is statistically significant $(p<0.01)$

${ }^{b}$ The difference between these groups is statistically significant $(p<0.05)$

c The difference between these groups is not statistically significant $(p>0.05)$

${ }^{d}$ The pairwise differences between these groups are statistically significant $(p<0.01)$

patients with no PC decision and lowest for patients with both a $\mathrm{PC}$ decision and a visit to a $\mathrm{PC}$ unit.

The results of the regression models are presented in Table 3. The models confirm the negative association between the $\mathrm{PC}$ decision and service usage prior to death, as well as between PC unit appointments and service usage prior to death, even after considering potential control variables, such as age and cancer site. On average, patients with a PC decision and an appointment to a PC unit had 15-24\% less ED visits and 56-64\% fewer inpatient days than the patients without a $\mathrm{PC}$ decision.

\section{Discussion}

In this assessment of the treatment of cancer patients at a Finnish university hospital, a PC decision to initiate a palliative intention for the treatment decreased the number of ED visits and inpatient days in a secondary/tertiary care hospital. Patients without a PC decision also died more often in a secondary or tertiary care hospital compared to the patients with a PC decision. The usage of health care services was further decreased if the patient had an appointment to a PC outpatient unit in addition to a PC decision. 
Table 2 Timing of the palliative care decision and the proportion of patients visiting a PC unit (\%)

\begin{tabular}{lll}
$\begin{array}{l}\text { Time between the PC } \\
\text { decision and death }\end{array}$ & $\begin{array}{l}\text { All patients with PC decision } \\
N \text { (\% of all patients) }\end{array}$ & $\begin{array}{l}\text { Patients with PC } \\
\text { outpatient unit } \\
\text { appointment } \\
N(\% \text { patients with } \\
P C \text { decision within } \\
\text { the timeframe) }\end{array}$ \\
\hline$<14$ days & $171(22 \%)$ & $17(10 \%)$ \\
$14-30$ days & $141(18 \%)$ & $50(35 \%)$ \\
$31-90$ days & $206(27 \%)$ & $105(51 \%)$ \\
$91-180$ days & $113(15 \%)$ & $75(66 \%)$ \\
$>180$ days & $142(18 \%)$ & $102(72 \%)$ \\
\hline
\end{tabular}

These results give an indication that a PC decision and an appointment to a $\mathrm{PC}$ outpatient unit may improve the quality of EOL care. However, it must be kept in mind that this conclusion applies on an aggregate level; on the individual level ED visits and hospitalizations may still be very well justified.

Internationally, the terminology of the PC period and its timing and content are not uniform. We chose to divide patients according to the timing of $\mathrm{PC}$ decisions and service usage by using time periods before death on clinical grounds and thus complying with most of the previous studies; however, the lack of strict recommendations on this timing makes comparison between previous studies and the present study somewhat difficult. Regarding the timing of the $\mathrm{PC}$ initiation, in two previous studies $[15,17]$ early PC referral was defined as a referral to $\mathrm{PC} \geq 30$ days, whereas in the study by Alsirafy and coworkers [16] the timing of PC referrals were categorized as early (> 90 days before death), intermediate (30-90 days before death) and late ( $<30$ days before death). In the study by Nieder and co-workers [18], three months before death was chosen as a time point to distinguish between an early and late PC. However, the timing of the PC period should be considered together with the content of the PC period, that is, whether patients received only treatments managing symptoms, or also disease-modifying treatments. These studies have not made a distinction between the patients receiving early integrated PC (during the active oncologic treatments), or late PC (after discontinuation of active oncologic treatments). No systematic early integrated PC was offered at $\mathrm{HUCH}$ during the time period of this study, although early integration has since been recommended by the clinical practice guidelines of the American Society of Clinical Oncology (ASCO), as well as the Lancet Commission of integration of oncology and PC $[13,20]$. Therefore, our cohort only represents PC introduced after the termination of anti-cancer treatments;

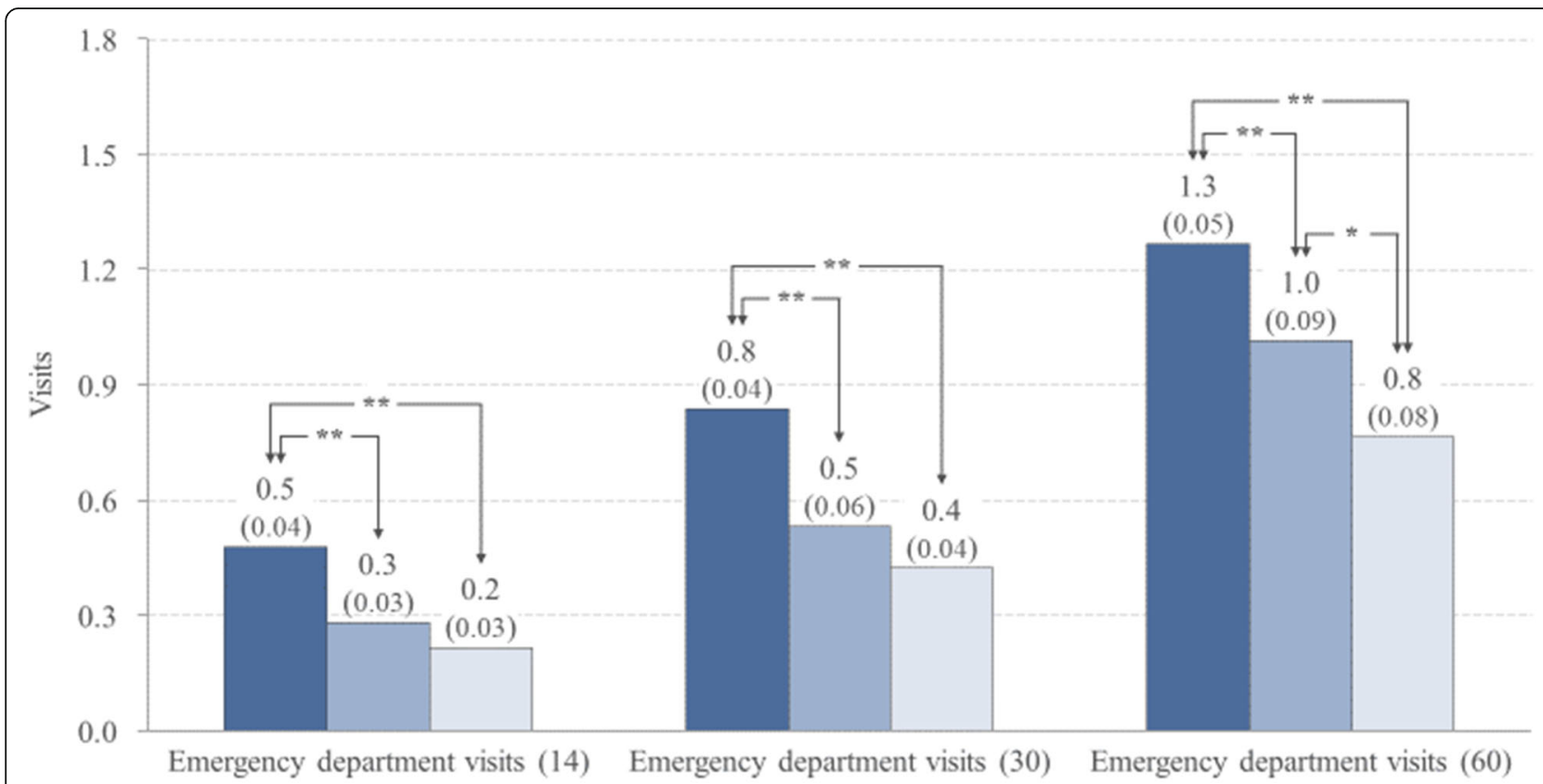

\section{No PC decision $\square$ PC decision $\square$ PC decision and appointment to a PC unit}

Fig. 1 Mean number of emergency department visits 14, 30, and 60 days before the death of patients with no PC decision, with a PC decision and with both a PC decision and visit to a PC unit before the time frame under consideration. Standard errors of the mean in parentheses. ${ }^{*}$ The pairwise comparison of the mean number of inpatient days is statistically significant $(p<0.05){ }^{* *}$ The pairwise comparison of the mean number of inpatient days is statistically significant $(p<0.01)$ 


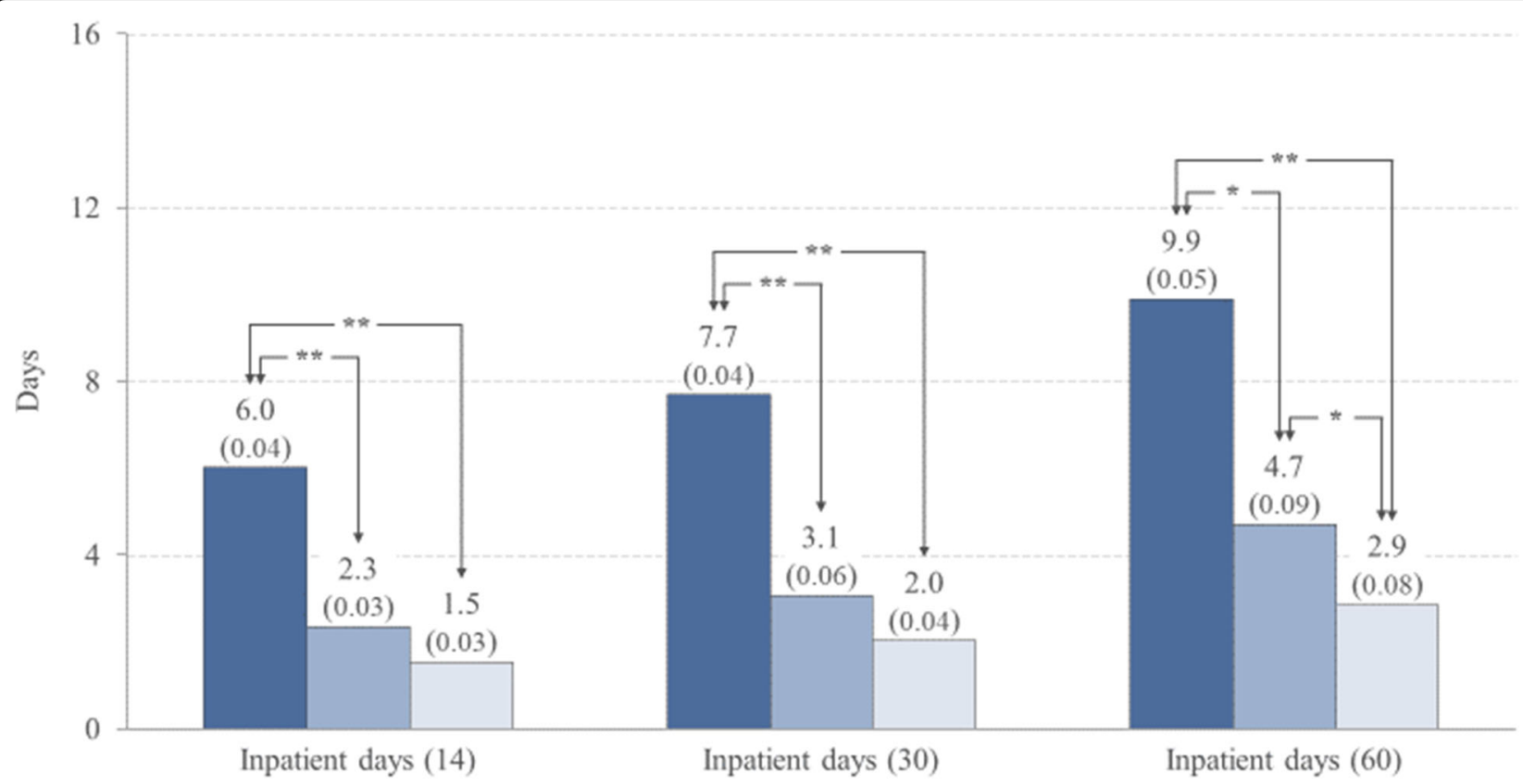

No PC decision $\square$ PC decision $\square$ PC decision and appointment to a PC unit

Fig. 2 Mean number of inpatient days 14, 30, and 60 days before the death of patients with no PC decision, with a PC decision and with both a PC decision and a visit to a PC unit before the time frame under consideration. Standard errors of the mean in parentheses. ${ }^{*}$ The pairwise comparison of the mean number of inpatient days is statistically significant $(p<0.05) * *$ The pairwise comparison of the mean number of inpatient days is statistically significant $(p<0.01)$

although the current evidence and recommendations highlight the importance of providing PC early and integrating it with disease modifying therapies. It is due to this limitation and the fact that most of the PC decisions were made quite close to death (for $67 \%$ of patients who had a PC decision, it was made within the last 3 months of life) that we chose to study the effect of the PC decision and the PC unit appointment with binary (yes/no) variables. This approach loses some information compared to an approach using the exact time lags between the PC decision and PC unit appointment and death in the statistical modeling. However, using this approach meant that the results were more robust and statistical significance could be detected.

We have earlier demonstrated with this same cohort of patients [19] that a PC decision initiating the palliative goal for care was frequently made, but occurred late [11]: the median time from the PC decision to death was 46 days. Patients with no or a very late PC decision $(<30$ days) received more aggressive cancer treatments at the EOL and made fewer visits to the PC unit. Only 37\% of these patients visited the PC unit. In this study, we further show that patients with no or very late PC decision not only receive more aggressive treatments at the EOL but also use more hospital services and have a higher risk of dying in an acute-care setting. These are often considered to be indicators of a poor quality of end of life care [21].

Despite the introduction of PC only after discontinuation of active oncological treatments in our cohort, we did observe the benefit of $\mathrm{PC}$ decisions in reducing the ED visits and inpatient days in the hospital, especially during the last months of life. A referral to the PC outpatient unit further decreased the ED visits and inpatient days. The reduction in the average number of inpatient days per patient was significant (5-7 days per patient). The reduction in the average number of ED visits per patient was $0.3-0.5$ visits. Even a small reduction in the number of ED visits, however, is significant in economic terms: for this study population it would mean approximately 200 fewer ED visits during the last month of life. In addition, we believe that every unnecessary visit to an ED during the last weeks of life are burdensome for the patient. However, the coefficients of determination (adjusted R2) of the regression models are relatively low - especially in the model for ED visits indicating that there is considerable variation in the data that this model does not capture. A systematic review and meta-analysis has indicated that PC services decrease the likelihood of ED visits [3]. An earlier study of cancer patients in Finland also showed that a visit to the PC outpatient clinic facilitated the connection with 
Table 3 Results of the regression model expressed as the proportional change (\%) in the patients' services usage 14, 30 and 60 days prior to death resulting from an increase in the covariates by $1 \%$. In the case of binary variables, the coefficient depicts the proportional changed in the service in each diagnosis group compared to breast cancer patients

\begin{tabular}{|c|c|c|c|c|c|c|}
\hline \multirow[b]{3}{*}{ Number of days before death } & \multicolumn{6}{|c|}{ Dependent variable } \\
\hline & \multicolumn{3}{|c|}{ Emergency department visits } & \multicolumn{3}{|c|}{ Inpatient days } \\
\hline & 14 & 30 & 60 & 14 & 30 & 60 \\
\hline Age & $-0.2^{\mathrm{a}}$ & -0.1 & $-0.2^{b}$ & -0.3 & -0.1 & $-0.4^{b}$ \\
\hline Days from diagnosis to death & 0.0 & 0.0 & 0.0 & 0.0 & -0.1 & -0.1 \\
\hline \multicolumn{7}{|c|}{ Binary variable: Diagnosis groups (reference category: Breast cancer) } \\
\hline Cancers of urinary tract & -0.4 & 1.0 & $20.2^{\mathrm{b}}$ & 9.2 & 25.8 & 42.7 \\
\hline Colorectal cancers & 4.0 & 7.9 & 9.1 & -5.1 & 16.9 & 10.4 \\
\hline Gynecological cancers & 3.2 & -1.6 & -8.7 & 1.3 & 11.7 & 25.9 \\
\hline Head \& Neck (H\&N) & -10.2 & -16.7 & -18.5 & -30.6 & -29.8 & -8.1 \\
\hline Lung & 8.7 & 10.8 & 7.9 & 9.0 & 12.8 & 13.2 \\
\hline Lymphomas & -1.9 & 2.0 & 5.7 & $50.8^{b}$ & $60.3^{b}$ & $64.2^{\mathrm{b}}$ \\
\hline Melanoma and other skin cancers & -0.6 & -4.9 & -7.9 & -24.1 & -26.2 & -23.8 \\
\hline Others & -0.6 & 5.8 & 5.3 & 33.4 & $81.9^{\mathrm{a}}$ & $89.6^{\mathrm{a}}$ \\
\hline Primary CNS malignancies & $-11.7^{\mathrm{b}}$ & $-17.8^{\mathrm{a}}$ & $-22.1^{\mathrm{a}}$ & $-44.1^{\mathrm{a}}$ & $-38.1^{\mathrm{a}}$ & $-39.4^{\mathrm{a}}$ \\
\hline Prostate cancers & 6.6 & 10.3 & 13.6 & 7.6 & 12.2 & 15.4 \\
\hline Sarcomas & -11.7 & $-19.2^{b}$ & -19.7 & -32.7 & -24.7 & -25.6 \\
\hline Upper gastrointestinal & 6.8 & 8.7 & 12.2 & 5.1 & 22.1 & 20.6 \\
\hline \multicolumn{7}{|c|}{ Binary variable: PC categories (reference category: 'no PC decision') } \\
\hline PC-decision & $-12^{\mathrm{a}}$ & $-18.6^{\mathrm{a}}$ & $-13.4^{a}$ & $-47.1^{\mathrm{a}}$ & $-57.6^{a}$ & $-51.1^{\mathrm{a}}$ \\
\hline PC-decision and admission to PC unit & $-15.3^{\mathrm{a}}$ & $-21.9^{\mathrm{a}}$ & $-24.2^{\mathrm{a}}$ & $-56^{\mathrm{a}}$ & $-63.4^{\mathrm{a}}$ & $-64.4^{\mathrm{a}}$ \\
\hline \multicolumn{7}{|l|}{ Test statistics } \\
\hline Adjusted $R^{2}$ & 0.06 & 0.08 & 0.06 & 0.13 & 0.18 & 0.16 \\
\hline F-stat & 4.45 & 6.13 & 4.98 & 10.16 & 14.16 & 12.02 \\
\hline Residual standard error & 0.35 & 0.44 & 0.53 & 1.10 & 1.08 & 1.14 \\
\hline
\end{tabular}

${ }^{\mathrm{a}}$ Significant at $0.01,{ }^{\mathrm{b}}$ Significant at 0.05

primary care services and tended to decrease ED visits and resource usage of the tertiary care hospital [14]. Both these earlier studies are in line with our results. We suggest that although a switch to a palliative goal for care may modify the EOL care arrangements of a patient, a sufficiently early contact with the PC services might have an even higher impact [10].

Early PC (initiated $>1$ to $>3$ months prior to death depending on the study) has been shown to be associated with fewer hospitalizations, earlier DNR designation, and an increased likelihood of dying at home or in a hospice instead of a hospital or an ICU [15-18]. In line with the previous studies, in our study, patients without a PC decision and especially those without any contact to the PC unit were more likely to die in a secondary or tertiary hospital ward. However, in the present study, the majority of the patients died in a primary care ward as there were only a few hospices or wards specializing in EOL care available during that time. Likewise, dying at home was rare due to the lack of specialized palliative home care teams.

Patients dying of cancer use the resources of hospitals - often for a good reason - but any reduction in the utilization of hospital wards is also beneficial from an economic perspective [22]. Indeed, it has been shown that palliative home care support or a proactive PC program reduces hospital use and the total costs of care at the EOL $[9,23]$. We did not carry out a cost benefit analysis in this study, but this important aspect warrants investigation in future studies.

There are some limitations to our study. One limitation is that the study was conducted on a random sample of the entire cohort. However, the sample of about 1000 patients was considered large enough to detect statistically significant differences between the patient groups, as this ensured that there would be over 100 patients in all the categories that were critical for the study (the number of patients with no PC decision, and 
patients with PC decision and an appointment to the PC unit). A random sample was chosen instead of the entire cohort because the manual collection of data from unstructured texts in medical records and death certificates proved so time-consuming that we would have needed more than two experts for the data collection. We considered the division of data collection among several experts to be a risk for the homogeneity of the data, and therefore chose to proceed with a sample.

In addition, the results do not contain the number of ED visits or inpatient days in primary care services since this information is not in the hospital databases. Furthermore, we could not exclude the possibility of some sudden deaths or deaths due to complications in the secondary or tertiary hospital; however, according to previous studies this would explain only a small proportion of deaths [24]. The lack of data on the quality of life is also a limitation. Finally, the analysis exploits the "benefit of hindsight" where the date of death is known. Thus, making recommendations on this basis for the future care of living patients is not possible without existing accurate prognostication as a part of clinical practice. The strength of the study is a relatively large sample size. The study cohort represent a population-based real-life situation comparable to epidemiological incidence of oncological diseases found within the population.

The retrospective chart review is one of the most reliable forms of research into PC and associated outcomes, due to the very high recruitment rate: once the approach is set and agreed, the desired number of cases can be gathered with very few exceptions.

\section{Conclusions}

Our study revealed that although for most cancer patients a PC decision (i.e. the decision to alter the treatment goal to palliative) was made for less than half of the patients, the decisions made were in collaboration with a PC team. The lack of a PC decision or postponing it to the last weeks of life reflected a significantly increased risk of visits to an ED, more inpatient days in a secondary or tertiary care hospital, and further, dying in a secondary or tertiary care ward. Early integrated PC should be offered more systematically to ensure a timely $\mathrm{ACP}$ and access to palliative and EOL care.

\section{Abbreviations \\ PC: Palliative care; EOL: End-of-life; ED: Emergency Department; ACP: Advance care plan; DNR: Do-not-resuscitate; ICU: Intensive care unit; HUCH: Helsinki University Central Hospital}

\section{Acknowledgments}

M.A. Elizabeth Nyman is acknowledged for language revision.

\section{Authors' contributions}

All authors (OMH, RL-L, LG, OH, SV, KT-K, EKR, JTL, TS) participated in the design of the study, interpretation of the data and read and approved the final manuscript. $\mathrm{OH}$ and $\mathrm{LG}$ carried out the manual data collection. $R-L L$ and
SV performed the statistical analyses. OMH and R-LL drafted and revised the manuscript, and the tables and the figures were revised by all the authors.

\section{Funding}

TS has received grants from the State Research Funding for Helsinki University Hospital [Y1018XTS15, Y1018XTS16], and TS and the study group from the Finnish Cancer Society [170114]. With the grants, OH and LG have carried out the data collection, and R-LL and SV performed the analyses, taken part in interpretation of the data as well as writing of the manuscript.

\section{Availability of data and materials}

All data and material related to the manuscript have been archived and maintained by the authors at the University hospital of Helsinki, according to organizational and ethical regulations. The raw data of this article is archived by the corresponding author and will not be published so as to preserve

patients' privacy. Upon request the authors will share the data in suitable way.

\section{Ethics approval and consent to participate}

Not applicable; the present study is based on hospital registry data, and, since the data has already been collected for clinical purposes, no patient interventions were performed; therefore, the legislation does not mandate any ethics committee approval. However, the institutional board of $\mathrm{HUCH}$ evaluated the study protocol and gave the permission to conduct it according to the rules of the Helsinki declaration.

\section{Consent for publication}

Not applicable.

\section{Competing interests}

The authors report no conflicts of interest.

\section{Author details}

'Department of Oncology and Radiotherapy, Turku University Hospital and Department of Clinical Oncology, University of Turku, PO Box 52, Fl-20521 Turku, Finland. ${ }^{2}$ Nordic Healthcare group, Helsinki, Finland. ${ }^{3}$ Department of Palliative Care, Comprehensive Cancer Center, Helsinki University Hospital, and Faculty of Medicine, Helsinki University, Helsinki, Finland. ${ }^{4}$ Tuusula Health Care Centre, Tuusula, Finland. ${ }^{5}$ Center of Oncology, Kuopio University Hospital, Kuopio, Finland. ${ }^{6}$ Department of Clinical Oncology, Oulu University Hospital, Oulu, Finland. ${ }^{7}$ Department of Oncology, Palliative Care Unit, Tampere University Hospital and Faculty of Medicine and Health Technology, University of Tampere, Tampere, Finland.

Received: 28 October 2019 Accepted: 17 March 2020

Published online: 24 March 2020

\section{References}

1. Barbera L, Taylor C, Dudgeon D. Why do patients with cancer visit the emergency department near the end of life? CMAJ. 2010;182(6):563-8

2. Earle CC, Park ER, Lai B, Weeks JC, Ayanian JZ, Block S. Identifying potential indicators of the quality of end-of-life cancer care from administrative data. JCO. 2003:21(6):1133-8.

3. Henson LA, Gao W, Higginson IJ, Smith M, Davies JM, Ellis-Smith C, et al. Emergency department attendance by patients with cancer in their last month of life: a systematic review and meta-analysis. JCO. 2015;33(4):370-6.

4. Brumley R, Enguidanos S, Jamison P, Seitz R, Morgenstern N, Saito S, et al. Increased satisfaction with care and lower costs: results of a randomized trial of in-home palliative care. J Am Geriatr Soc. 2007;55:993-1000.

5. Spilsbury K, Rosenwax L, Arendts G, Semmens JB. The association of community-base palliative care with reduced emergency department visits in the last year of life varies by patient factors. Ann Emerg Med. 2017;69(4): 416-25.

6. Riolfi M, Buja A, Zanardo C, Marangon CF, Manno P, Baldo V. Effectiveness of palliative home-care services in reducing hospital admissions and determinants of hospitalization for terminally ill patients followed up by a palliative home-care team: a retrospective cohort study. Palliat Med. 2014; 28(5):403-11.

7. Seow H, Brazil K, Sussman J, Pereira J, Marshall D, Austin PC, et al. Impact of community based, specialist palliative care teams on hospitalisations and emergency department visits late in life and hospital deaths: a pooled analysis. BMJ. 2014;348:g3496. 
8. Seow H, Dhaliwal G, Fassbender K, Rangrej J, Brazil K, Fainsinger R. The effect of community-based specialist palliative care teams on place of care. J Palliat Med. 2016;19(1):16-21.

9. Maetens A, Beernaert K, De Schreye R, Faes K, Annemans L, Pardon K, et al. Impact of palliative home care support on the quality and costs of care at the end of life: a population-level matched cohort study. BMJ Open. 2019;9: e025180.

10. Temel JS, Greer JA, Muzikansky A, Gallagher ER, Admane S, Jackson VA, et al. Early palliative care for patients with metastatic non-small-cell lung cancer. N Engl J Med. 2010;363:733-42.

11. Wright AA, Zhang B, Ray A, Mack JW, Trice E, Balboni T, et al. Associations between end-of-life discussions, patient mental health, medical care near death, and caregiver bereavement adjustment. JAMA. 2008;300(14):1665-73.

12. Scibetta C, Kerr K, Mcguire J, Rabow MW. The costs of waiting: implications of the timing ot palliative care consultation among a cohort of decedents at a comprehensive cancer center. J Palliat Med. 2016;19(1):69-75.

13. Kaasa S, Aapro M, Albreht T, Anderson R, Bruera E, Caraceni A, et al. Integration of oncology and palliative care. A Lancet Oncology Commission. Lancet Oncol. 2018;Nov;19(11):e588-653.

14. Hirvonen OM, Alalahti JE, Syrjänen KJ, Jyrkkiö SM. End-of-life decision guiding the palliative care of cancer patients visiting emergency department in South Western Finland: a retrospective cohort study. BMC Palliative Care. 2018;17:128

15. Poulose JV, Kyung Do Y, Soek Hui Neo P. Association between referral-todeath interval and location of death of patients referred to a hospital-based specialist palliative care service. J Pain Symptom Manag. 2013:46(2):173-81.

16. Alsirafy SA, Raheem AA, Al-Zahrani AS, Mohammed AA, Sherisher MA, ElKashif AT, et al. Emergency department visits at the end of life of patients with terminal cancer: pattern, causes and avoidability. Am J Hosp Palliat Med. 2016;33(7):658-62.

17. Blackhall LJ, Read P, Stukenborg G, Dillon P, Barclay J, Romano A, et al. CARE track for advanced cancer: impact and timing of an outpatient palliative care clinic. J Palliat Med. 2016;19(1):57-63.

18. Nieder C, Tollåli T, Haukland E, Reigstad A, Randi Flatoy L, Engljähringer K. Impact of early palliative interventions on the outcomes of care for patients with non-small cell lung cancer. Support Care Cancer. 2016;24:4385-91.

19. Hirvonen O, Leskelä R-L, Grönholm L, Haltia O, Rissanen A, TyyneläKorhonen $\mathrm{K}$, et al. Assessing the utilization of the decision to implement a palliative goal for the treatment of cancer patients during the last year of life at Helsinki University Hospital: a historic cohort study. Acta Oncol. 2019; 58:1699-1705

20. Ferrell BR, Temel JS, Temin S, Alesi ER, Balboni TA, Basch EM, et al. Integration of palliative care into standard oncology care: American society of clinical oncology clinical practice guideline update. J Clin Oncol. 2017; 35(1):96-112.

21. Earle CC, Neville BA, Landrum MB, Souza JM, Weeks JC, Block SD, et al. Evaluating claims-based indicators of the intensity of end-of-life cancer care. Int J Qual Health Care. 2005;17:505-9.

22. Huang J, Boyd C, Tyldesley S, Zhang-Salomons J, Groome PA, Mackillop WJ. Time spent in hospital in the last six months of life in patients who died of cancer in Ontario. JCO. 2002;20(6):1584-92.

23. Cassel JB, Kerr KM, McClish DK, Skoro N, Johnson S, Wanke C, et al. Effect of a home-based palliative care program on healthcare use and costs. JAGS. 2016;64:2288-95.

24. Torres VB, Vassalo J, Silva UVA, Caruso P, Torelly AP, JMM T, et al. Outcomes in critically ill patients with cancer-related complications. PloS ONE. 2016; 11(10):e0164537.

\section{Publisher's Note}

Springer Nature remains neutral with regard to jurisdictional claims in published maps and institutional affiliations.

Ready to submit your research? Choose BMC and benefit from:

- fast, convenient online submission

- thorough peer review by experienced researchers in your field

- rapid publication on acceptance

- support for research data, including large and complex data types

- gold Open Access which fosters wider collaboration and increased citations

- maximum visibility for your research: over $100 \mathrm{M}$ website views per year

At BMC, research is always in progress.

Learn more biomedcentral.com/submissions 